\title{
Haiti Acute and Emergency Care Conference: descriptive analysis of an acute care continuing medical education program
}

\author{
Lia I Losonczy', Sarah Williams ${ }^{2}$, Alfred Papali ${ }^{3}$, Corey A Costantino ${ }^{4}$, L Nathalie Colas ${ }^{5}$, Bhavesh M Patel ${ }^{6}$, \\ Donald F Zimmer ${ }^{7}$, Shannon R Olwine ${ }^{8}$, Zena Davidson ${ }^{9}$, John W Wilson ${ }^{8}$, Michael T McCurdy ${ }^{3}$, Marc E Augustin ${ }^{5}$, \\ Nathan D Nielsen ${ }^{10}$ \\ 1 Department of Emergency Medicine, Department of Anesthesia \& Critical Care Medicine, The George Washington University Medical Center, \\ Washington, D.C., USA, ${ }^{2}$ Department of Pulmonary \& Critical Care, Atrium Health, Charlotte, North Carolina, USA, ${ }^{3}$ Division of Pulmonary \& Critical \\ Care, University of Maryland School of Medicine, Baltimore, Maryland, USA, ${ }^{4}$ Saint Lûc Hospital, Port-au-Prince, Haiti, 5 Department of Critical Care \\ Medicine, Mayo Clinic Arizona, Scottsdale, Arizona, USA, ${ }^{6}$ Department of Emergency Medicine, Memorial Hospital of South Bend, South Bend, \\ Indiana, USA, 7 Division of Infectious Diseases, Mayo Medical School, Rochester, Minnesota, USA, ${ }^{8}$ Department of Anesthesiology, University of \\ British Columbia, Vancouver, British Columbia, Canada, ${ }^{9}$ Department of Emergency Medicine, University of Maryland School of Medicine, Baltimore, \\ Maryland, USA, ${ }^{10}$ Division of Pulmonary Disease, Critical Care and Environmental Medicine, Tulane School of Medicine, New Orleans, Louisiana, USA \\ Keywords: global health
}

https://doi.org/10.29392/joghr.3.e2019012

\section{Journal of Global Health Reports}

Vol. 3, 2019

\section{Background}

Several disasters over the past decade have highlighted the need for strong acute-care systems in Haiti. As part of a multifaceted approach to improving national acute-care training, the Research and Education consortium for Acute Care in Haiti (REACH) launched the inaugural Haiti Acute and Emergency Care Conference (HAECC).

\section{Methods}

REACH is a Haitian-led, multinational collaboration based out of Saint Lûc Hospital in Port-au-Prince. The first HAECC was held in April, 2017. Pre- and post-course evaluation consisted of subjective and objective components. Differences between pre- and post-responses were determined using McNemar's test of paired proportions.

\section{Results}

57 participants from 21 hospitals in five Haitian departments were included. The majority (37/58, 63.8\%) were physicians. Most (33/57, 57.9\%) had no prior training in acute or emergency care, but 8/57 (14.0\%) had taken ATLS/ACLS, 11/57 (19.3\%) had taken a formal course not internationally recognized, and only $1 / 57$ (1.8\%) had completed acute care specialty training. $43.7 \%(25 / 57)$ reported routine access to point-of-care ultrasound. Following course completion, participants felt significantly more comfortable managing basic emergency conditions (up to $25 / 57,43.9 \%$ increase, $P<0.01$ ) and using ultrasound (up to $30 / 57,52.6 \%$ increase, $P<0.01$ ), but improvements on objective testing were not significant (ranging from $-2(-3.5 \%, P=1.00)$ to $+5(8.7 \%, P=0.15)$ change).

\section{Conclusions}

While continued quality review is necessary for future iterations of the conference, the inaugural HAECC provided a useful "first pass" for current front-line providers in Haiti.

Haiti has the lowest health indices in the Western Hemisphere and, in the past decade, has experienced major strains on its the health care system due to natural disasters (earthquake, hurricanes) and epidemics (cholera, zika, chikungunya). Separate from these occurrences is a baseline high burden of critical and emergency illness typical of many low-middle income countries (LMICs). ${ }^{1}$ Yet, Haiti lacks an integrated emergency medical system. ${ }^{2}$ These discrepancies have highlighted the need for strong acute care (defined as emergency and critical care) systems in Haiti.

The historical misconception that acute care is neither appropriate nor cost-effective for LMICs has been chal- lenged by a growing body of evidence demonstrating otherwise. Traditional thinking prioritizes preventive care over acute care for LMICs. ${ }^{3,4}$ The literature, however, shows not only a strong medical necessity in LMICs for comprehensive acute care systems ${ }^{5}$, but also a positive impact on population health and a reduced burden of disease when implemented effectively and efficiently in a cost-effective manner. ${ }^{5-9}$ Moreover, the implementation of targeted evidenceor guideline-based acute care interventions in LMICs can improve patient outcomes and enhance processes of care. ${ }^{10,11}$ 
While the tangible benefits remain clear, numerous barriers to establishing robust acute care systems in LMICs still exist. Limitations in infrastructure, equipment, human resources and postgraduate training are common. ${ }^{1,2,12,13}$ In Haiti, there is currently only one certified Emergency Medicine residency program ${ }^{14}$ and no formal intensive care program. There is also no requirement for continuing medical education (CME; personal communication, Dr. Marc Augustin).

As part of a comprehensive, multifaceted approach to improving acute care training and providing acute care CME in Haiti, the Research and Education consortium for Acute Care in Haiti (REACH) launched the inaugural Haiti Acute and Emergency Care National Conference in 2017.

\section{METHODS}

REACH is a Haitian-led, multinational collaboration based out of Saint Lûc Hospital in Port-au-Prince. A group of Haitian, Canadian, and American acute care nurses and physicians, all with extensive clinical experience in Haiti, designed a two-day course emphasizing management of common emergency conditions, point-of-care ultrasound, and basic procedural skills. Evaluation of course effectiveness was determined by pre- and post-course assessments.

The inaugural Haiti Acute and Emergency Care Conference (HAECC) was held on April 28-29th, 2017. Physicians, nurses and trainees from 22 institutions around the country were invited to participate for a nominal fee. The course curriculum, consisting of 13 didactic sessions and 12 small group sessions with skills stations (Table 1), was developed by consensus. Several nursing-specific sessions were held. Ten of thirteen lectures were presented exclusively by Haitian physicians. Each lecture was reviewed a priori for accuracy and visual aesthetics by a paired Haitian and North American expert. All lectures were posted on a purposebuilt website (http://haecc.org/).

Pre- and post-course evaluation consisted of subjective and objective components. Topics for subjective assessment included comfort with image interpretation, point-of-care ultrasound, and management of common emergency conditions. Level of comfort was determined by 5-point Likert scale with responses subsequently dichotomized to "comfortable" and "not comfortable.” Topics for objective knowledge assessment emphasized management of common emergency conditions, EKG and chest x-ray interpretation. Questions were in multiple choice and free text formats with responses dichotomized into "correct" or "not correct," as determined by four REACH faculty members. Disagreement was resolved by consensus. Differences between preand post-conference responses were determined using McNemar's test of paired proportions. Statistical significance was defined as $P<0.05$. All statistical analyses were performed with Stata MP Statistical Software (Release 11, College Station, TX, 2009).

\section{RESULTS}

A total of 58 participants, representing 21 hospitals, from five administrative departments in Haiti, participated in the course. The majority $(37 / 58,63.8 \% ; 16$ general doctors, 11 internists, 2 generalists, 1 emergency medicine, 1 pulmonologist, 1 urologist, 5 medical students) were physicians or physicians-in-training. Sixteen (27.6\%) were nurses or nurses-in-training. The remainder did not identify their background. Fifty-seven participants completed pre- and post-course surveys and were included in the analysis. Most (33/57, 57.9\%) had no prior training in acute or emergency care, but $8 / 57$ (14.0\%) had taken ATLS/ACLS, 11/57 (19.3\%) had taken a formal course not internationally recognized, and only $1 / 57$ (1.8\%) had completed acute care specialty training. Significant minorities reported routine access to point-of-care ultrasound $(25 / 57,43.7 \%)$ and x-ray $(22 / 57$, $38.6 \%)$, but none to CT scanners. Reliable access ranged widely to intravenous fluids (40/57, 70.2\%), intravenous antibiotics (37/57, 64.9\%), blood products (10/57, 17.5\%), mechanical ventilators $(10 / 57,17.5 \%)$, and noninvasive ventilation (3/57, 5.26\%). Only 15/57 (26.32\%) reported reliable electricity, and 14/57 (24.56\%) reliable internet access.

Following course completion, participants felt significantly more comfortable using point of care ultrasound, specifically in the skill domains of bedside echo (26/57 (43.9\% increase), $P<0.01)$, gaining vascular access $(25 / 57$ (43.9\% increase), $P<0.01)$, differentiating causes of hypotension (14/57 (19.3\% increase), $P<0.01)$, and using it for a FAST exam (34/57 (52.6\% increase), $P<0.01)$. Participants also felt more comfortable managing a number of emergency conditions post course, such as cardiac arrest (34/ 57 (43.9\% increase), $P<0.01$ ), acute coronary syndrome (40/ 57 (40.2\% increase), $P<0.01)$, and sepsis (49/57 (43.9\% increase), $P<0.01)$. They also felt significantly more comfortable utilizing other therapeutics and diagnostics such as invasive and noninvasive ventilation. Please see Table 2 for details. Improvements on objective testing regarding diagnosis and management of various causes of critical illness, such as different causes of shock (ranging from -2 , $+5(-3.5 \%, 8.7 \%)$ change, $P=0.15, P=1.0)$, trauma $(28 / 57,0 \%$ increase, $P=1.0)$, and sepsis $(31 / 57(2.7 \%$ increase, $P=0.7)$ ) were not significant (Table 2 ).

Participants had variable feelings toward gearing future course content toward international best practice guidelines $(14 / 57,24.6 \%)$, or to evidence primarily from LMICs (10/57, 17.5\%), or both (12/57, $21.1 \%$ both). The vast majority of participants expressed interest in conducting research $(55 / 57,96.5 \%)$ and establishing a website $(55 / 57,96.5 \%)$ for communication and information sharing related to the course.

\section{DISCUSSION}

Haiti's health care system is a complex mixture of public and private health care institutions, many with multi-national or foreign non-governmental support, constantly in flux pending the availability of funding, staff, and the changing face of infrastructure. Compounded by poverty, vulnerability to severely disruptive natural disasters, and an overwhelming majority of physicians trained in Haiti leaving the country within 5 years of graduating medical school, ${ }^{15}$ these factors make building a robust acute care system in Haiti both difficult and imperative. 
Table 1. Topics covered in acute care conference and teaching format

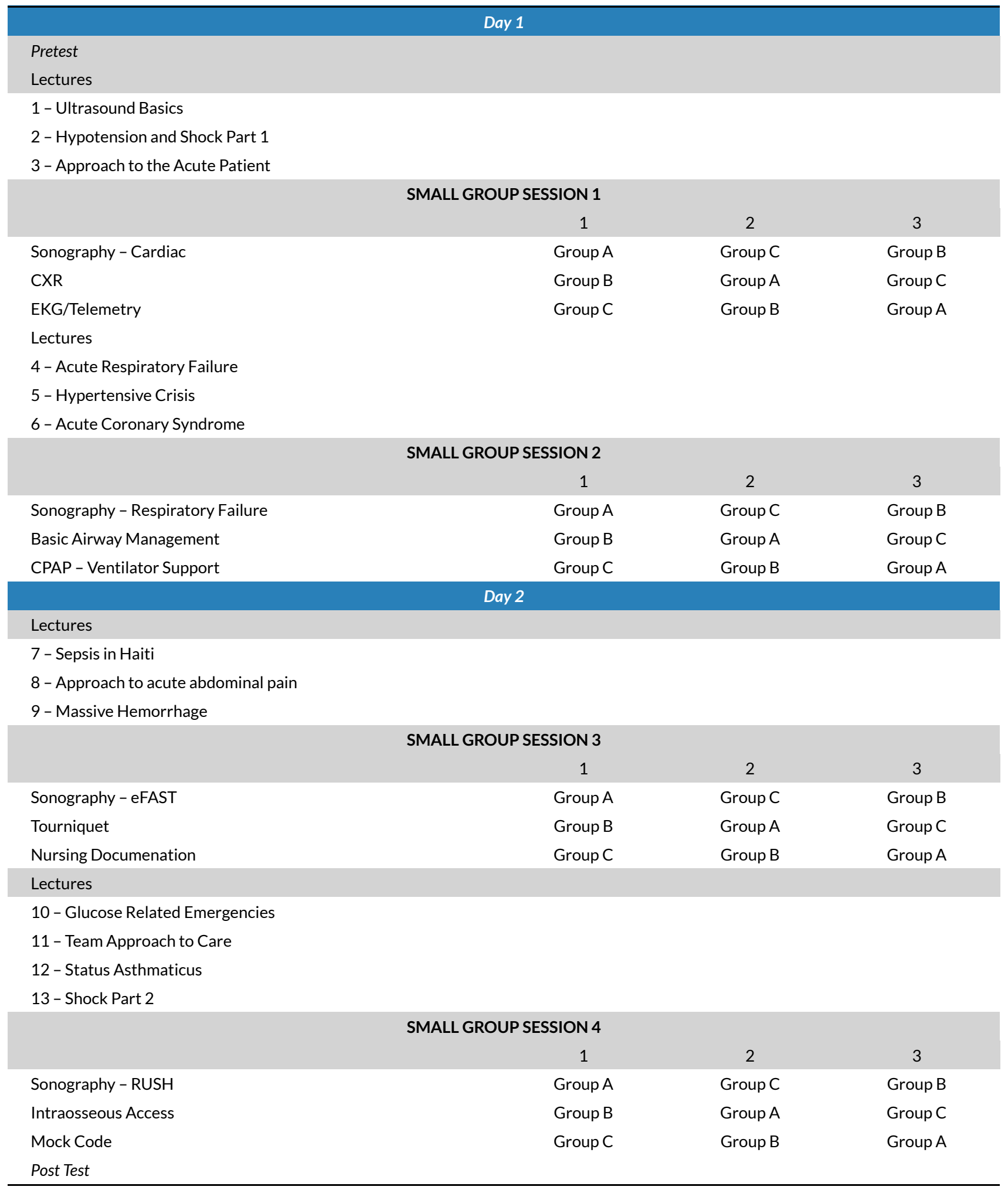

Training a cadre of specialized acute care providers will be an essential component of a sustainable health care system in Haiti. The Emergency Medicine residency recently developed in Haiti's Central Plateau is a very positive first step in this direction. However, only $51 \%$ of Haitians live within 50 kilometers of a tertiary care hospital, ${ }^{16}$ so increasing the capacity of non-acute care clinicians to provide time-sensitive emergency interventions has the potential to significantly improve acute care outcomes throughout
Haiti. In a recent review of trauma care systems in LMICs, task shifting and targeted training of non-specialty providers were identified as a potential key mechanism for addressing human resource limitations in LMICs. ${ }^{3}$

This two-day course allowed for significantly improved subjective comfort with managing common emergency conditions and use of point-of-care ultrasound, a modality that is much more common than CT scanners and even x-rays in the majority of Haitian healthcare facilities. 
Table 2. Pre- and post-test assessment of level of comfort and objective knowledge difference

\begin{tabular}{|c|c|c|c|c|}
\hline & $\begin{array}{l}\text { Pre-Course N } \\
(\%)\end{array}$ & $\begin{array}{l}\text { Post-Course N } \\
\text { (\%) }\end{array}$ & $\begin{array}{l}\text { Percent } \\
\text { Change \% }\end{array}$ & $P$-value \\
\hline \multicolumn{5}{|l|}{ Subjective skills assessment } \\
\hline Comfortable using an ultrasound for echo & $1(1.8)$ & $26(45.6)$ & 43.8 & $<0.01$ \\
\hline Comfortable using ultrasound for hypotension & $3(5.3)$ & $14(24.6)$ & 19.3 & $<0.01$ \\
\hline Comfortable using ultrasound for FAST & $4(7.0)$ & $34(59.6)$ & 52.6 & $<0.01$ \\
\hline Comfortable using ultrasound for vascular access & $0(0 \%)$ & $25(43.9)$ & 43.9 & $<0.01$ \\
\hline Comfortable interpreting an EKG & $15(26.3)$ & $28(49.1)$ & 22.8 & $<0.01$ \\
\hline Comfortable interpreting an CXR & $25(43.7)$ & $44(77.2)$ & 33.5 & $<0.01$ \\
\hline Comfortable using NIPPV & $2(3.5)$ & $30(52.6)$ & 49.1 & $<0.01$ \\
\hline Comfortable intubating & $10(17.5)$ & $28(49.1)$ & 31.6 & $<0.01$ \\
\hline Comfortable managing a ventilator & $5(8.8)$ & $28(49.1)$ & 40.3 & $<0.01$ \\
\hline Comfortable performing ACLS & $9(15.8)$ & $34(59.6)$ & 43.8 & $<0.01$ \\
\hline Comfortable managing abdominal pain & $35(61.4)$ & $42(73.7)$ & 12.3 & 0.05 \\
\hline Comfortable managing hypertensive crisis & $46(80.7)$ & $52(91.2)$ & 10.5 & 0.09 \\
\hline Comfortable managing glucose emergency & $46(80.7)$ & $54(94.7)$ & 14.0 & 0.01 \\
\hline Comfortable managing hemorrhage & $35(61.4)$ & $48(84.2)$ & 22.8 & $<0.01$ \\
\hline Comfortable managing Acute Coronary Syndrome & $17(29.8)$ & $40(70.2)$ & 40.4 & $<0.01$ \\
\hline Comfortable managing respiratory failure & $27(47.3)$ & $46(80.7)$ & 33.4 & $<0.01$ \\
\hline Comfortable managing sepsis & $29(50.9)$ & $49(86.0)$ & 35.0 & $<0.01$ \\
\hline Comfortable managing hock & $32(56.1)$ & $52(91.2)$ & 35.1 & $<0.01$ \\
\hline \multicolumn{5}{|l|}{ Objective assessment: correct diagnosis* } \\
\hline Septic shock & $45(79.0)$ & $45(79.0)$ & 0 & 0.74 \\
\hline Hemorrhagic shock & $51(89.5)$ & $49(86.0)$ & -3.5 & 1.00 \\
\hline Cardiogenic shock & $45(79.0)$ & $50(87.7)$ & 8.7 & 0.15 \\
\hline Identify MI (all) & $19(33.0)$ & $24(42.1)$ & 9.1 & 0.09 \\
\hline Identify MI (doctors) & $19(51.4)$ & $23(62.2)$ & 10.8 & 0.15 \\
\hline Identify PTX (all) & $7(12.3)$ & $19(33.0)$ & 20.7 & $<0.01$ \\
\hline Identify PTX (doctors) & $7(18.9)$ & $17(46.0)$ & 27.1 & $<0.01$ \\
\hline \multicolumn{5}{|l|}{$\begin{array}{l}\text { Objective assessment: correct management } \\
\text { (doctors only)* }\end{array}$} \\
\hline Sepsis & $30(81.1)$ & $31(83.8)$ & 2.7 & 0.70 \\
\hline Respiratory distress & $17(46.0)$ & $21(56.8)$ & 10.8 & 0.48 \\
\hline Trauma & $28(75.68)$ & $28(75.68)$ & 0 & 1.0 \\
\hline Chest pain & $23(62.2)$ & $28(73.0)$ & 10.8 & 0.16 \\
\hline
\end{tabular}

MI - myocardial infarction, PTX - pneumothorax

*Answers marked correct if at least $2 / 3$ responses accepted by four REACH instructors.

Participants specifically increased their level of comfort utilizing ultrasound for bedside echo, differentiation of hypotension, vascular access, and FAST exam in trauma. While ultrasound availability has been increasing dramatically in LMICs, and as evidenced by the relatively high rates of ultrasound access reported by the participants, the routine use of ultrasound in the clinical setting has been primarily limited by lack of adequate training. ${ }^{17}$ In addition to this intensive two-day course, participants have access to an open access course website (HAECC.org) where all lectures including those on ultrasound are available for them for reference and review. While more in-depth training and continued quality review are necessary for incorporating ultrasound education into clinical practice in Haiti, this course provided a useful first course for many of the par- ticipants. Participants also felt significantly more comfortable diagnosing and managing a range of acute disease processes, from cardiac arrest and respiratory failure to sepsis and abdominal pain. Increasing their ability to comfortably manage these acute illnesses may provide better outcomes for patients, however further study would need to be conducted.

Objective knowledge gain was not significant, however, perhaps reflecting the small sample size. Participants were given open access to course content to facilitate asynchronous didactic learning. Our findings also highlight that participants seek content relevant to both high-income and low-income country settings. Best practice guidelines for LMICs are limited by a paucity of evidence, but there exists 
a strong appetite amongst Haitian clinicians for conducting clinical research (96\% in our cohort).

A key to this conference's success was Haitian leadership and participation, which provided legitimacy and contextappropriate course content. International partners largely played a support role. Moreover, the emphasis on nursing developed the team-building potential for empowering nurses to recognize and manage common acute care conditions, which may be especially relevant in situations where physicians are not always available. ${ }^{18}$

While LMICs reflect great heterogeneity in the availability of acute and emergency care education, the majority have a profound need for context-specific instruction for their front-line practitioners. The success of the first HAECC refutes the commonly espoused dogma that principles, techniques, and technology of "high tech" medical care is irrelevant to the resource-limited setting. The goal of the REACH collaborative is to establish a consistently highquality didactic framework that not only will be sustainable over time in Haiti, but that can provide a template for similar sustainable programs in other LMICs.

There were several limitations of the course and the resulting evaluation. The HAECC was primarily geared towards and taught by physicians, though over $30 \%$ of the learners were nurses. With subjective responses, it is possible the subjects would be biased to respond in the affirmative with regards to their comfort level in the skills assessed. It is also possible given the small sample size that by chance we happened to reach subjects particularly adept at this form of learning. However, there is no systematic reason to believe that is the case. Moreover, the inaugural course lacked formal endorsement by the Haitian Ministry of Health, an issue being addressed for future conferences. Lastly, long-term knowledge retention and skill acquisition were not assessed.

\section{CONCLUSIONS}

While formal Haitian Emergency Medicine or Critical Care postgraduate training will eventually provide the foundation for a comprehensive, national acute care system, the inaugural HAECC provided a useful "first pass" for current front-line providers of acute care in Haiti. Continued quality review is necessary for future iterations, but this conference serves as an important first step towards establishing formal acute care CME programs in Haiti.

\section{ACKNOWLEDGEMENTS}

The authors wish to thank Ms. Magalie Cine, Ms. Shella Rock, Ms. Marie Iderle Fenistor and Dr. Gerson Pyram for their invaluable assistance in conference preparation, as well as our many Haitian colleagues who lectured and/or participated in the conference.

\section{ETHICAL APPROVAL}

This manuscript summarizes results from an anonymous post-conference survey as part of a quality improvement project. IRB approval was not required.

\section{FUNDING}

None.

\section{COMPETING INTERESTS}

The authors have completed the Unified Competing Interest form at http://www.icmje.org/coi_disclosure.pdf (available on request from the corresponding author) and declare no conflicts of interest.

\section{CORRESPONDENCE TO:}

Lia I Losonczy, MD, MPH

Department of Emergency Medicine

George Washington University

Department of Anesthesia \& Critical Care Medicine

2120 L Street, Suite 450

Washington, DC 20037

USA

lia.losonczy@gmail.com 


\section{REFERENCES}

1. Murthy S, Leligdowicz A, Adhikari NKJ. Intensive Care Unit capacity in low-income countries: A systematic review. PLOS ONE. 2015;10(1):e0116949. $\underline{\mathrm{d}}$ oi:10.1371/journal.pone.0116949

2. De Wulf A, Aluisio AR, Muhlfelder D, Bloem C. Emergency care capabilities in north east Haiti: A cross-sectional observational study. Prehosp Disaster Med. 2015;30(6):553-559. doi:10.1017/s1049023x1500 $\underline{5221}$

3. Reynolds TA, Stewart B, Drewett I, et al. The impact of trauma care systems in low-and middleincome Countries. Annu Rev Public Health. 2017;38(1):507-532. doi:10.1146/annurev-publhealt h-032315-021412

4. Kobusingye OC, Hyder AA, Bishai D, Hicks ER, Mock C, Joshipura M. Emergency medical systems in low- and middle-income countries: recommendations for action. Bull World Health Organ. 2005;83:626-631.

5. Hirshon JM, Risko N, Calvello EJ, et al. Health systems and services: the role of acute care. Bull World Health Organ. 2013;91(5):386-388. doi:10.2471/ blt.12.112664

6. Bickler SN, Weiser TG, Kassebaum N, Higashi H, Chang DC, Barendregt JJ, et al. Global Burden of Surgical Conditions. In: Debas HT, Donkor P, Gawande A, Jamison DT, Kruk ME, Mock CN, eds. Essential Surgery: Disease Control Priorities, Third Edition. Vol 1. The International Bank for Reconstruction and Development / The World Bank; 2015.

7. Murthy S, Adhikari NK. Global health care of the critically ill in low-resource settings. Ann Am Thorac Soc. 2013;10(5):509-513. doi:10.1513/annalsats.20130 7-246ot

8. Kerry VB, Sayeed S. Leveraging opportunities for critical care in resource-limited settings. Glob Heart. 2014;9(3):275-279. doi:10.1016/i.gheart.2014.09.002

9. Cubro H, Somun-Kapetanovic R, Thiery G, Talmor $\mathrm{D}$, Gajic O. Cost effectiveness of intensive care in a low resource setting: A prospective cohort of medical critically ill patients. World J Crit Care Med. 2016;5(2):150-164. doi:10.5492/wjccm.v5.i2.150
10. Baatiema L, Chan CKY, Sav A, Somerset S. Interventions for acute stroke management in Africa: a systematic review of the evidence. Syst Rev. 2017;6(1):213. doi:10.1186/s13643-017-0594-4

11. Papali A, West TE, Verceles AC, et al. Treatment outcomes after implementation of an adapted WHO protocol for severe sepsis and septic shock in Haiti. $J$ Crit Care. 2017;41:222-228. doi:10.1016/j.jcrc.2017.0 $\underline{5.024}$

12. Vukoja M, Riviello E, Gavrilovic S, et al. A survey on critical care resources and practices in low- and middle-income countries. Glob Heart. 2014;9(3):337-342.e5. doi:10.1016/i.gheart.2014.08.0 $\underline{02}$

13. Dat VQ, Long NT, Giang KB, Diep PB, Giang TH, Diaz JV. Healthcare infrastructure capacity to respond to severe acute respiratory infection (SARI) and sepsis in Vietnam: A low-middle income country. J Crit Care. 2017;42:109-115. doi:10.1016/j.jcrc.2017.07.020

14. Rouhani S, Marsh RH, Checkett K, Edmond C, Rimpel L. Emergency medicine education in lowresource settings: A residency program model from Haiti. Ann Glob Health. 2015;81(1):50. doi:10.1016/j.a ogh.2015.02.622

15. Partners in Health. Responding to the Emergency at L'Hôpital Université d'Etat d'Haïti: A First Step in Rebuilding Haiti's Public Health Care System. Accessed February 28, 2018. https://parthealth.3cdn.n et/d9640a9f7321cc1440 9rm6i0ci5.pdf

16. Tansley G, Schuurman N, Amram O, Yanchar N. Spatial access to emergency services in low- and middle-income countries: A GIS-based analysis. PLoS ONE. 2015;10(11):e0141113. doi:10.1371/journal.pon e. 0141113

17. Shah S, Bellows BA, Adedipe AA, Totten JE, Backlund BH, Sajed D. Perceived barriers in the use of ultrasound in developing countries. Crit Ultrasound J. 2015;7(1):28. doi:10.1186/s13089-015-0028-2

18. Crisp N, Chen L. Global supply of health professionals. N Engl J Med. 2014;370(10):950-957. do i:10.1056/neimra1111610 